\title{
Polymorphisms in the MTHFR gene are associated with recurrence risk in lymph node-positive breast cancer patients
}

\author{
Ali Suner' \\ Hakan Buyukhatipoglu' \\ Gokmen Aktas' \\ Tulay Kus' \\ Mustafa Ulaslı \\ Serdar Oztuzcu² \\ Mehmet Emin Kalender' \\ Alper Sevinc' \\ Seval Kul ${ }^{3}$ \\ Celaletdin Camci' \\ 'Division of Medical Oncology, \\ Department of Internal Medicine, \\ Gaziantep Oncology Hospital, \\ University of Gaziantep, Gaziantep, \\ Turkey; ${ }^{2}$ Department of Medical \\ Biology, Faculty of Medicine, \\ University of Gaziantep, Gaziantep, \\ Turkey; ${ }^{3}$ Department of Biostatistics, \\ Faculty of Medicine, University of \\ Gaziantep, Gaziantep, Turkey
}

This article was published in the following Dove Press journal:

OncoTargets and Therapy

9 September 2016

Number of times this article has been viewed

Purpose: The aim of this study is to clarify the relationship between recurrence risk of breast cancer and methylenetetrahydrofolate reductase (MTHFR) C677T polymorphisms.

Patients and methods: Breast cancer patients who had undergone surgery in Gaziantep University Oncology Hospital between June 2005 and June 2012 were followed-up and retrospectively enrolled in this study. Blood samples were collected from all patients to assess MTHFR C677T polymorphisms. Stage according to tumor-node-metastasis system, estrogen receptor, progesterone receptor, human epidermal growth factor receptor 2 status, grade of disease, menopausal status, and administered chemotherapy or hormonal therapy were recorded. Effects of these parameters on recurrence risk were evaluated using univariate analysis and multivariate binary logistic regression model.

Results: Association of MTHFR C677T polymorphisms with recurrence risk was evaluated in 298 patients whose median age was 47 years (range: $21-79$ years). In all patients, age (odds ratio $[\mathrm{OR}]=0.953, P=0.005)$ and $\mathrm{N} 3$ lymph node status $(\mathrm{OR}=6.293, P=0.001)$ were found to affect the recurrence risk. While MTHFR homozygote genotype did not have an effect on recurrence risk in all patients, increased risk was observed in lymph node-positive subgroup $(\mathrm{OR}=4.271 ; 95 \%$ CI 1.515-12.023; $P=0.006)$. Adjusting for age, tumor size $(\mathrm{T})$, and node status (N), MTHFR homozygote genotype had more statistically significant risk for recurrence ( $\mathrm{OR}=3.255$; 95\% CI 1.047-10.125; $P=0.041$ ).

Conclusion: MTHFR TT genotype was found to be associated with increased recurrence risk in patients with lymph node-positive breast cancer.

Keywords: breast cancer, methylenetetrahydrofolate reductase, MTHFR, rs9651118 polymorphism, recurrence risk

\section{Introduction}

Early-stage breast cancer is the most probable curative disease when compared to other cancer types; however, still the most principal problem in the disease management is the possible recurrence, and the most critical question for clinicians is "what are the predicting parameters of the long-term recurrence?". Traditional parameters such as stage according to the pathological tumor-node-metastasis (TNM) system, the number of metastatic lymph nodes, the extent of metastases in the lymph nodes, histological type and grade of the tumor, resection margins including the location and minimum distance of the margin, vascular invasion, and expression of estrogen receptor (ER), progesterone receptor (PR), human epidermal growth factor receptor 2 (HER-2), and Ki-67 are used to decide the adjuvant treatment choice and also to predict breast cancer recurrence and survival. ${ }^{1}$ In addition, there have been untraditional markers predicting breast cancer recurrence.

\footnotetext{
Correspondence: Ali Suner

Division of Medical Oncology,

Department of Internal Medicine,

Gaziantep Oncology Hospital,

University of Gaziantep, Bestepe District,

Onkoloji Street, Number I5, Sahinbey/

Gaziantep, TR-27310, Turkey

Email dralisuner@hotmail.com
} 
Personalized medicine in oncology focuses on methylenetetrahydrofolate reductase (MTHFR), which is accepted as one of the untraditional predicting markers for cancer survival..$^{2-5}$ Methylenetetrahydrofolates play an essential role in de novo synthesis of purines and the pyrimidine nucleoside; hence, they have an integral role in DNA biosynthesis and repair and maintenance of DNA stability. They participate in the remethylation of homocysteine to methionine, the precursor of $S$-adenosylmethionine, which is the principal methyl donor in most cellular reactions. ${ }^{6}$ Folate deficiency induces carcinogenesis via decreasing essential tumor suppressor activation and increasing inappropriate proto-oncogene activation and leads to the development of several epithelial cell malignancies, including the breast, colorectal, ovary, pancreas, brain, lung, esophagus, and cervix, by provoking DNA strand breakage and chromosomal aberrations. ${ }^{71}$ Functional polymorphisms in the genes encoding one-carbon metabolism enzymes are MTHFR (C677T), methionine synthase (MTR A2756G), methionine synthase reductase (MTRR A66G), and thymidylate synthase, which influence folate metabolism. ${ }^{12}$ MTHFR plays a central role in intracellular folate homeostasis and metabolism by irreversibly catalyzing the conversion of 5,10-methylenetetrahydrofolate (5,10-MTHF) to 5-methyltetrahydrofolate. ${ }^{13} \mathrm{C} 677 \mathrm{~T}$ is associated with decrease in MTHFR activity and increase in the levels of homocysteine and A1298C, which is also related to the reduction of MTHFR activity. Two common polymorphisms of MTHFR genes are related to increased risk of breast cancer, ${ }^{14-16}$ although existing studies suggested contradiction with these findings. ${ }^{17-20}$ These polymorphisms could also play a role in the prediction of breast cancer survival. We aimed to assess the role of MTHFR C677T polymorphisms in predicting the recurrence of breast cancer.

\section{Patients and methods}

Pathologically confirmed nonmetastatic breast cancer patients treated in Gaziantep University Oncology Hospital between June 2005 and June 2012 were consecutively enrolled retrospectively for this study. The study was reviewed and approved by the Independent Ethics Committee of Gaziantep University, and written informed consent was obtained from all of the patients. All patients had undergone simple mastectomy or modified radical mastectomy and axillary lymph node dissection. Stage based on the TNM system, ER, PR, HER-2 status, and grade were recorded. Patients received anthracycline-based chemotherapy with or without taxanes. Administered chemotherapy and consequent hormonal therapy were noted. Patients receiving adjuvant 5 -fluorouracil (5-FU) were also separately noted. Five milliliter blood samples were collected into sterile siliconized vacuum tubes containing $2 \mathrm{mg} / \mathrm{mL}$ disodium ethylenediaminetetraacetic acid. Genomic DNA was immediately extracted from whole blood. Genetic variants of rs1801133 at chromosome 1:11796321 in the MTHFR gene (amino acid translation Ala140Val) were studied by using Genotyping the Fluidigm Digital Array. These polymorphisms were evaluated by using genomic DNA with a 96.96 dynamic array on the BioMark HD system (Fluidigm, South San Francisco, CA, USA). This trial was designed to assess whether MTHFR polymorphism influences the recurrence risk of breast cancer together with the other predicting parameters of recurrence.

\section{Statistical analysis}

First, univariate analyses were performed to compare the two groups; Student's $t$-tests (for continuous variables) and chi-square tests (for categorical variables) were used. Second, multivariate binary logistic regression models were used for determining possible risk factors. Clinically related variables were included in the model if significant at the $10 \%$ level according to the univariate analysis results. Multicollinearity was checked by calculating variance inflation factors. All univariate analyses were performed in SPSS for windows Version 22.0. A two-sided $P$-value $<0.05$ was defined as statistically significant.

\section{Results}

A total of 298 patients were enrolled in this study. Their mean age was 47 years (range 21-79 years). Fifty-eight (19.5\%) patients showed recurrence. There was a statistically significant difference in the categories of age, menopausal status, grade, size of tumor (T), and axillary lymph node status $(\mathrm{N})$ according to univariate analysis. However, no statistically significant difference was observed in the categories of ER expression, PR expression, HER-2 expression, use of 5-FU in adjuvant setting, and MTHFR C677T polymorphisms in terms of recurrence (Table 1). Multivariate binary logistic regression model is given in Table 2 for all patients. Grade was not added to the model because of the strong correlation with the lymph node status. Adjusting for menopausal status, use of 5-FU, ER expression, tumor size, age (odds ratio $[\mathrm{OR}]=0.953, P=0.005$ ), and N3 lymph node status (OR $=6.293, P=0.001)$ appeared to affect recurrence risk (Table 2). Adjusted $R^{2}$ for this model was $24 \%$.

\section{Analysis of lymph node-positive patients}

Excluding the lymph node-negative (N0) patients, 189 patients were analyzed for the recurrence according to risk factors. Univariate analysis for age, menopausal status, use of 
Table I Univariate analysis of all patients in terms of recurrence

\begin{tabular}{|c|c|c|c|c|}
\hline \multirow[t]{2}{*}{ Risk factors } & \multicolumn{2}{|l|}{ Recurrence } & \multirow[t]{2}{*}{ OR (95\% Cl) } & \multirow[t]{2}{*}{$P$-value } \\
\hline & Present & Absent & & \\
\hline Age, years & $44.38 \pm 11.59$ & $50.21 \pm 11.59$ & $0.954(0.928-0.981)$ & 0.001 \\
\hline \multicolumn{5}{|c|}{ Menopausal status } \\
\hline Pre & $4 \mid(70.7)$ & $122(50.8)$ & $2.333(1.256-4.334)$ & 0.007 \\
\hline Post & $17(29.3)$ & 118 (48.2) & I (reference) & \\
\hline \multicolumn{5}{|l|}{ Use of 5-FU } \\
\hline Received & $22(42.3)$ & $56(28.6)$ & $1.833(0.975-3.447)$ & 0.060 \\
\hline Not received & $30(57.7)$ & $140(7 \mid .4)$ & I (reference) & \\
\hline \multicolumn{5}{|l|}{ ER expression } \\
\hline Positive & $36(62.1)$ & $177(74.1)$ & I (reference) & \\
\hline Negative & $22(37.9)$ & $62(25.9)$ & $1.745(0.954-3.192)$ & 0.071 \\
\hline \multicolumn{5}{|l|}{ PR expression } \\
\hline Positive & $4 \mid(70.7)$ & $169(70.7)$ & $0.999(0.532-1.876)$ & 0.997 \\
\hline Negative & $17(29.3)$ & $70(29.3)$ & I (reference) & \\
\hline \multicolumn{5}{|c|}{ HER-2 expression } \\
\hline Positive & $17(29.3)$ & $68(28.7)$ & $1.030(0.548-1.938)$ & 0.926 \\
\hline Negative & $41(70.7)$ & $169(71.3)$ & I (reference) & \\
\hline \multicolumn{5}{|l|}{ Grade, $P=0.033$} \\
\hline 1 & $\mathrm{I}(\mathrm{I} .8)$ & $21(8.8)$ & I (reference) & \\
\hline 2 & $22(40)$ & $123(5 \mid .5)$ & $3.756(0.480-29.375)$ & 0.207 \\
\hline 3 & $32(58.2)$ & $95(39.7)$ & $7.074(0.915-54.712)$ & 0.061 \\
\hline \multicolumn{5}{|c|}{ Tumor size $(T), P=0.048$} \\
\hline 1 & $3(5.2)$ & $35(14.6)$ & I (reference) & \\
\hline 2 & $36(62.1)$ & $143(59.6)$ & $2.937(0.855-10.093)$ & 0.087 \\
\hline 3 & $16(27.6)$ & $37(15.4)$ & $5.045(1.352-18.827)$ & 0.016 \\
\hline 4 & $3(5.2)$ & $25(10.4)$ & $1.400(0.261-7.516)$ & 0.695 \\
\hline \multicolumn{5}{|c|}{ Lymph node status $(N), P<0.00$} \\
\hline 0 & $13(22.4)$ & $96(40)$ & I (reference) & \\
\hline I & $14(24.1)$ & $87(36.2)$ & $1.188(0.529-2.668)$ & 0.676 \\
\hline 2 & $16(27.6)$ & $38(15.8)$ & $3.109(1.366-7.078)$ & 0.007 \\
\hline 3 & $15(25.9)$ & $19(7.9)$ & $5.830(2.392-14.210)$ & $<0.001$ \\
\hline \multicolumn{5}{|l|}{ MTHFR, $P=0.176$} \\
\hline $\mathrm{CC}$ & $27(46.6)$ & $123(5 \mid .2)$ & I (reference) & \\
\hline $\mathrm{CT}$ & $21(36.2)$ & $96(40)$ & $0.997(0.53 \mid-1.870)$ & 0.991 \\
\hline $\mathrm{TT}$ & $10(17.2)$ & $21(8.8)$ & $2.169(0.917-5.129)$ & 0.078 \\
\hline
\end{tabular}

Note: Recurrence data presented as $\mathrm{n}(\%)$ or mean $\pm \mathrm{SD}$.

Abbreviations: OR, odds ratio; 5-FU, 5-fluorouracil; ER, estrogen receptor; PR, progesterone receptor; HER-2, human epidermal growth factor receptor; MTHFR, methylenetetrahydrofolate reductase; $\mathrm{Cl}$, confidence interval.

Table 2 Multivariate binary logistic regression model for the risk factors of recurrence

\begin{tabular}{|c|c|c|c|c|c|c|}
\hline \multirow[t]{2}{*}{ Risk factors } & \multirow[t]{2}{*}{ B } & \multirow[t]{2}{*}{ SE } & \multirow[t]{2}{*}{$P$-value } & \multirow[t]{2}{*}{ OR } & \multicolumn{2}{|c|}{ 95\% $\mathrm{Cl}$ for $\mathrm{OR}$} \\
\hline & & & & & Lower & Upper \\
\hline MTHFR (TT) & 0.527 & 0.517 & 0.308 & 1.693 & 0.615 & 4.663 \\
\hline MTHFR (CT) & -0.149 & 0.403 & 0.710 & 0.861 & 0.391 & 1.896 \\
\hline Age & -0.048 & 0.017 & 0.005 & 0.953 & 0.922 & 0.986 \\
\hline 5-FU (I) & 0.521 & 0.366 & 0.154 & 1.683 & 0.822 & 3.448 \\
\hline ER (I) & 0.309 & 0.387 & 0.425 & 1.362 & 0.638 & 2.906 \\
\hline $\mathrm{T}(2$ vs I) & 0.554 & 0.689 & 0.422 & 1.740 & 0.451 & 6.718 \\
\hline $\mathrm{T}(3$ vs I) & 0.464 & 0.761 & 0.542 & 1.590 & 0.358 & 7.063 \\
\hline T (4 vs I) & -0.848 & 0.963 & 0.378 & 0.428 & 0.065 & 2.828 \\
\hline$N(I$ vs 0$)$ & -0.075 & 0.464 & 0.871 & 0.927 & 0.374 & 2.303 \\
\hline $\mathrm{N}(2$ vs 0$)$ & 0.872 & 0.500 & 0.081 & 2.391 & 0.897 & 6.375 \\
\hline$N(3$ vs 0$)$ & 1.839 & 0.568 & 0.001 & 6.293 & 2.066 & 19.167 \\
\hline
\end{tabular}

Notes: $B$ is the estimated logit coefficient. SE is the standard error of the coefficient. $P$-value is the significance level of the coefficient.

Abbreviations: SE, standard error; OR, odds ratio; MTHFR, methylenetetrahydrofolate reductase; 5-FU, 5-fluorouracil; ER, estrogen receptor; T, tumor size; N, lymph node status; $\mathrm{Cl}$, confidence interval.
5-FU, ER expression, PR expression, HER-2 expression, grade, $\mathrm{T}, \mathrm{N}$, and MTHFR is summarized in Table 3. MTHFR homozygote genotype has an OR of 4.271 compared with MTHFR wild genotype in univariate analysis. Analysis revealed that MTHFR C677T polymorphisms, age, T3 tumor size, and N2-N3 lymph node involvement were prognostic indicators for recurrence. Variables with $P<0.10$ were added to multivariate binary logistic regression model (Table 4). Adjusting for age, T, and N, MTHFR homozygote genotype still showed a statistically significant risk for recurrence (OR $=3.255 ; 95 \%$ CI 1.047-10.125; $P=0.041)$. Adjusted $R^{2}$ for this model was $22.1 \%$.

\section{Discussion}

Several studies evaluated the effects of mutations in the MTHFR gene, which plays a role in DNA methylation, on 
Table 3 Univariate analysis results after excluding N0 patients

\begin{tabular}{|c|c|c|c|c|}
\hline \multirow[t]{2}{*}{ Risk factors } & \multicolumn{2}{|l|}{ Recurrence } & \multirow[t]{2}{*}{ OR $(95 \% \mathrm{Cl})$} & \multirow[t]{2}{*}{$P$-value } \\
\hline & Present & Absent & & \\
\hline Age, years & $45.02 \pm 11.94$ & $49.29 \pm 12.02$ & $0.964(0.933-0.997)$ & 0.038 \\
\hline \multicolumn{5}{|c|}{ Menopausal status } \\
\hline Pre & $30(66.7)$ & $77(53.5)$ & I (reference) & \\
\hline Post & $15(33.3)$ & $65(46.5)$ & $0.575(0.285-\mid .158)$ & 0.121 \\
\hline \multicolumn{5}{|l|}{ Use of 5-FU } \\
\hline Received & 17 (4I.5) & $38(30.4)$ & $\mathrm{I} .622(0.782-3.36 \mathrm{I})$ & 0.194 \\
\hline Not received & $24(58.5)$ & $87(69.6)$ & I (reference) & \\
\hline \multicolumn{5}{|l|}{ ER expression } \\
\hline Positive & $29(64.4)$ & $103(72)$ & I (reference) & \\
\hline Negative & $16(35.6)$ & $40(28)$ & $1.42 \mid(0.698-2.893)$ & 0.333 \\
\hline \multicolumn{5}{|l|}{ PR expression } \\
\hline Positive & $35(77.8)$ & $99(69.2)$ & $1.556(0.708-3.419)$ & 0.271 \\
\hline Negative & $10(22.2)$ & $44(30.8)$ & I (reference) & \\
\hline \multicolumn{5}{|c|}{ HER-2 expression } \\
\hline Positive & 14 (3I.I) & $43(30.5)$ & $1.029(0.498-2.127)$ & 0.938 \\
\hline Negative & $31(68.9)$ & $98(69.5)$ & I (reference) & \\
\hline \multicolumn{5}{|l|}{ Grade, $P=0.037$} \\
\hline I & I (2.4) & $9(6.2)$ & I (reference) & \\
\hline 2 & $15(35.7)$ & $66(45.8)$ & $2.045(0.240-17.397)$ & 0.512 \\
\hline 3 & $26(61.9)$ & 69 (47.9) & $3.391(0.409-28.102)$ & 0.258 \\
\hline \multicolumn{5}{|c|}{ Tumor size $(T), P=0.002$} \\
\hline I & $2(4.4)$ & $19(13.2)$ & I (reference) & \\
\hline 2 & $26(57.8)$ & $83(57.6)$ & $2.976(0.649-13.636)$ & 0.160 \\
\hline 3 & $14(31.1)$ & $25(17.4)$ & $5.320(1.077-26.276)$ & 0.040 \\
\hline 4 & $3(6.7)$ & $17(11.8)$ & $1.676(0.249-11.266)$ & 0.595 \\
\hline \multicolumn{5}{|c|}{ Lymph node status $(N), P<0.00$ I } \\
\hline I & 14 (3।.I) & $87(60.4)$ & I (reference) & \\
\hline 2 & $16(35.6)$ & $38(26.4)$ & $2.617(1.161-5.895)$ & 0.020 \\
\hline 3 & $15(33.3)$ & $19(13.2)$ & $4.906(2.032-11.844)$ & $<0.001$ \\
\hline \multicolumn{5}{|l|}{ MTHFR, $P \leq 0.0 \mathrm{I}$} \\
\hline $\mathrm{CC}$ & $24(53.3)$ & $82(56.9)$ & I (reference) & \\
\hline $\mathrm{CT}$ & II (24.4) & $54(37.5)$ & $0.696(0.315-1.537)$ & 0.370 \\
\hline $\mathrm{TT}$ & $10(22.2)$ & $8(5.6)$ & $4.271(1.517-12.023)$ & 0.006 \\
\hline
\end{tabular}

Note: Recurrence data presented as $\mathrm{n}(\%)$ or mean \pm SD.

Abbreviations: OR, odds ratio; 5-FU, 5-fluorouracil; ER, estrogen receptor; PR, progesterone receptor; HER-2, human epidermal growth factor receptor; MTHFR, methylenetetrahydrofolate reductase; $\mathrm{Cl}$, confidence interval.

breast cancer pathogeneses, and fewer studies evaluated the effects on breast cancer prognosis. MTHFR enzyme activity may be responsible for these entities by different mechanisms. ER and PR status have been used widely as

Table 4 Multivariate analysis of lymph node-positive patients according to risk factors in terms of recurrence

\begin{tabular}{|c|c|c|c|c|c|c|}
\hline \multirow[t]{2}{*}{ Variables } & \multirow[t]{2}{*}{ B } & \multirow[t]{2}{*}{ SE } & \multirow[t]{2}{*}{$P$-value } & \multirow[t]{2}{*}{ OR } & \multicolumn{2}{|c|}{$95 \% \mathrm{Cl}$ for $\mathrm{OR}$} \\
\hline & & & & & Lower & $\overline{\text { Upper }}$ \\
\hline MTHFR (TT vs CC) & 1.180 & 0.579 & 0.041 & 3.255 & 1.047 & 10.125 \\
\hline MTHFR (CT vs CC) & -0.441 & 0.433 & 0.308 & 0.643 & 0.275 & 1.504 \\
\hline Age & -0.036 & 0.017 & 0.035 & 0.964 & 0.933 & 0.997 \\
\hline $\mathrm{T}(2$ vs I) & 0.884 & 0.808 & 0.274 & 2.422 & 0.497 & 11.806 \\
\hline $\mathrm{T}(3 \mathrm{vs} \mathrm{I})$ & 0.928 & 0.867 & 0.285 & 2.528 & 0.462 & 13.840 \\
\hline $\mathrm{T}(4$ vs I) & -0.329 & 1.038 & 0.751 & 0.719 & 0.094 & 5.499 \\
\hline$N(2$ vs I) & 1.026 & 0.446 & 0.021 & 2.791 & 1.165 & 6.684 \\
\hline$N(3$ vs I) & 1.480 & 0.505 & 0.003 & 4.392 & 1.632 & $|1.82|$ \\
\hline
\end{tabular}

Notes: $B$ is the estimated logit coefficient. SE is the standard error of the coefficient. $P$-value is the significance level of the coefficient.

Abbreviations: SE, standard error; OR, odds ratio; MTHFR, methylenetetrahydrofolate reductase; $\mathrm{T}$, tumor size; $\mathrm{N}$, lymph node status; $\mathrm{Cl}$, confidence interval. prognostic markers and indicators for management of breast cancer treatment, and loss of function of these genes is a poor prognostic for recurrence of breast cancer. Promoter hypermethylations resulting from the decrease of enzyme activity have been implicated as an underlying mechanism for the loss of these receptors. ${ }^{21,22}$ It has been claimed that breast carcinogenesis could be associated with alteration of ER receptor gene methylation patterns and global DNA methylation with reduction in MTHFR enzyme activity; thus, less folate is available for DNA methylation. ${ }^{23,24}$ MTHFR enzyme activity is $\sim 30 \%-40 \%$ in $677 \mathrm{TT}$ homozygote genotype, whereas it is $\sim 60 \%-70 \%$ in C677T heterozygote genotype. ${ }^{25}$ Therefore, decreased enzyme activity may be associated with increased recurrence risk. In our study, we demonstrated that MTHFR 677TT homozygote genotype is significantly associated with the increased risk of breast cancer recurrence and prognosis when assessed using all pathological and clinical parameters, which probably have an effect on recurrence risk score. 
Otherwise, there is influence of MTHFR gene on breast cancer survival as a direct target effect via widely used anticancer drugs, such as methotrexate and 5-fluorouracil, in combination chemotherapies. Optimal efficacy of fluoropyrimidines requires elevated intratumoral concentrations of 5,10-MTHF ${ }^{26}$ Lesser MTHFR enzymatic activity could theoretically favor an increase in intracellular 5,10-MTHFR concentrations. Accordingly, patients with mutated MTHFR genotypes may be more sensitive to fluoropyrimidine cytotoxicity and fluoropyrimidine responsiveness than wild-type genotype. ${ }^{27,28}$ While folate is antineoplastic before the diagnosis, it may enhance the tumor proliferation after tumor establishment. Thus, the effect of one-carbon metabolism on breast cancer survival may be complicated. In our study, it was shown that recurrence in patients who received 5-FUbased chemotherapy was not associated with MTHFR gene mutation. In addition, Shanghai Breast Cancer study showed that MTHFR genotypes were not associated with all-cause mortality in patients who received 5-FU and methotrexatebased chemotherapy consistent with our study. The 677TT genotype was associated with poor survival among those with late-stage disease (stage III-IV) in Chinese women but did not significantly affect the survival from early-stage disease consistent with our findings. ${ }^{29}$

A meta-analysis that was performed on Chinese population showed that MTHFR C677T polymorphism was significantly associated with breast cancer risk. ${ }^{30} \mathrm{~A}$ large meta-analysis including a total of 75 studies with 31,315 cases and 35,608 controls was assessed for the strength of association between C677T polymorphism and breast cancer risk. Accordingly, modest association between MTHFR C677T polymorphism and breast cancer was shown in all studies. Otherwise, subgroup analysis showed that there was a strong significant association between TT genotype and breast cancer (TT vs CC; OR $=1.26 ; 95 \%$ CI 1.06-1.51; $P=0.009$ ) in Asian population; however, this association was not observed in Caucasian population (TT vs CC; $\mathrm{OR}=1.08 ; 95 \%$ CI $0.99-1.14 ; P=0.05) .{ }^{31} \mathrm{Lu}$ et al examined whether several single nucleotide polymorphisms (SNPs) in the MTHFR gene are associated with risk and survival of 560 breast cancer patients compared with 560 healthy controls group. Participants were followed for 5 years; accordingly, it was found that one genetic marker was significantly associated with breast cancer survival. Patients with rs9651118 CC genotype had significantly decreased risk of death compared to the TT carriers when adjusted for age (hazard ratio $[\mathrm{HR}]=0.60$; 95\% CI 0.38-0.92). When adjusted for age, age at menarche, body mass index, family history of breast cancer, histological grade, ER status, PR status, and tumor size ( $<2 \mathrm{~cm}$ vs $>2 \mathrm{~cm}$ ), it was shown that rs 9651118 was an independent prognostic factor for breast cancer survival with adjusted HR of 0.63 (95\% CI $0.40-0.99 ; P=0.002)$. Axillary lymph node staging was not recorded, and tumor size was also stratified as only $<2 \mathrm{~cm}$ vs $>2 \mathrm{~cm}$ in this study. ${ }^{32}$ In our study, SNP of rs 1801133 on MTHFR gene was found to be associated with increased recurrence risk consistent with those studies; however, multivariate analysis with TNM staging system and other prognostic parameters should be used to obtain more consistent results like our study.

The study of Martin et al for evaluating the effect of SNP in MTHFR gene, C677T, and A1298C on survival in 248 operated Caucasian and African-American breast cancer patients showed that $\mathrm{C} 677 \mathrm{~T}$ was not significantly associated with breast cancer survival in the unstratified Cox regression analysis with adjustments for age at diagnosis, race, A1298C, body mass index, ER status, TNM stage, and chemotherapy. However, it was found that two polymorphisms in the MTHFR gene affect the survival of only ER-negative breast cancer patients $(\mathrm{HR}=2.70 ; 95 \%$ CI 1.17-6.23; $P=0.02) .{ }^{33}$ In this study, 677TT and 677CC alleles were not studied.

A large cohort study explored the role of dietary intakes of B vitamins (1,479 cases) and MTHFR genotypes $(\sim 1,065$ cases $)$ on survival in Caucasian breast cancer patients. Accordingly, the MTHFR 677T allele carriers had $31 \%$ decreased risk of death when compared to patients with the MTHFR $677 \mathrm{CC}$ genotype (HR $=0.69 ; 95 \% \mathrm{CI}$ 0.49-0.98). Additionally, it was examined whether the polymorphism-survival relationship differed by hormone receptor (ER/PR) status. Associations between the polymorphisms and survival showed no difference with respect to hormone receptor status. ${ }^{34}$

Another study performed on a Russian population showed that MTHFR C677T polymorphism was inversely associated with progression-free survival only among premenopausal breast cancer patients. ${ }^{35}$ Additionally, two other studies did not observe any relation between MTHFR gene C677T polymorphism and breast cancer survival. ${ }^{5,36}$ In these studies, 677TT and 677CC alleles were not assessed separately distinct from our study.

In a Turkish population, the effects of FV Leiden mutation (FVL), PT G20210A, and MTHFR C677T (heterozygote allele) on the disease-free survival in 197 breast cancer patients were assessed. Data regarding patient's age, menopausal status, tumor size, lymph node status, tumor stage, tumor grade, ER, PR, and HER-2 expression, FVL, PT G20210A and MTHFR C677T polymorphisms, and 
recurrence ratio of breast cancer were examined. Accordingly, there was no statistically significant difference between the categories of age, menopausal status, PR expression, FVL, and PT G20210A and MTHFR C677T polymorphisms in terms of recurrence $(P>0.05)$. MTHFR C677T polymorphism was not related to disease-free survival in breast cancer patients $(P=0.670) .{ }^{36}$ Subgroup analysis of lymph node-positive patients for recurrence risk was not performed in this study.

The aforementioned studies increasingly suggested that the effect of genetic polymorphism of folate metabolizing genes on breast cancer survival is variable in ethnic groups. In this regard, we evaluated the impact of MTHFR gene 677TT polymorphism on breast cancer survival in a population living in the southeast of Anatolia. No significant differences were revealed between MTHFR C677T polymorphism and recurrence risk when considering all pathologic and clinical parameters according to multivariant analysis consistent with other studies; on the other hand, subgroup analysis of our patients with MTHFR 677TT polymorphism showed increased recurrence risk in lymph node-positive patients. At the same time, MTHFR polymorphisms did not have any effect on the recurrence risk of patients who had received 5-FU-based regimen.

\section{Conclusion}

In Anatolian population, MTHFR rs9651118 TT genotype was found to be associated with increased recurrence risk in patients with lymph node-positive breast cancer.

\section{Disclosure}

The authors report no conflicts of interest in this work.

\section{References}

1. Engelhardt EG, Garvelink MM, de Haes JH, et al. Predicting and communicating the risk of recurrence and death in women with early-stage breast cancer: a systematic review of risk prediction models. $J$ Clin Oncol. 2014;32(3):238-250.

2. Wu NC, Su SM, Lin TJ, et al. Methylenetetrahydrofolate reductase C677T and A1298C polymorphisms and fluorouracil-based treatment in Taiwan colorectal cancer. Anticancer Drugs. 2015;26(8):888-893.

3. He HR, Chen SY, You HS, et al. Association between methylenetetrahydrofolate reductase polymorphisms and the relapse of acute lymphoblastic leukemia: a meta-analysis. Pharmacogenomics $J$. 2014;14(5): 432-438.

4. Osian G, Procopciuc L, Vlad L, Mocan T, Cristea PG. Correlation between C677T and A1298C mutations of the MTHFR gene and therapeutic prognostic elements in colorectal cancer. Chirurgia (Bucur). 2010; 105:373-378.

5. Knechtel G, Hofmann G, Gerger A, et al. Analysis of common germline polymorphisms as prognostic factors in patients with lymph node-positive breast cancer. J Cancer Res Clin Oncol. 2010;136(12):1813-1819.

6. Duthie SJ. Folate and cancer: how DNA damage, repair and methylation impact on colon carcinogenesis. J Inherit Metab Dis. 2011;34(1): 101-109.
7. Izmirli M. A literature review of MTHFR (C677T and A1298C polymorphisms) and cancer risk. Mol Biol Rep. 2013;40:625-637.

8. Shujuan Y, Jianxing Z, Xin-Yue C. Methylenetetrahydrofolate reductase genetic polymorphisms and esophageal squamous cell carcinoma susceptibility: a meta-analysis of case-control studies. PakJ Med Sci. 2013; 29(2):693-698.

9. Swartz MD, Peterson CB, Lupo PJ, et al. Investigating multiple candidate genes and nutrients in the folate metabolism pathway to detect genetic and nutritional risk factors for lung cancer. PLoS One. 2013;8(1):e53475.

10. Ziva Cerne J, Stegel V, Gersak K, Novakovic S. Lack of association between methylenetetrahydrofolate reductase genetic polymorphisms and postmenopausal breast cancer risk. Mol Med Rep. 2011;4(1): $175-179$.

11. Glynn SA, Albanes D. Folate and cancer - a review of the literature. Nutr Cancer. 1994;22:101-119.

12. Suzuki T, Matsuo K, Hirose K, et al. One-carbon metabolism-related gene polymorphisms and risk of breast cancer. Carcinogenesis. 2008; 29(2):356-362.

13. Goyette P, Sumner JS, Milos R, et al. Human methylenetetrahydrofolate reductase: isolation of cDNA, mapping and mutation identification. Nat Genet. 1994;7(2):195-200.

14. Boccia S, Hung R, Ricciardi G, et al. Meta- and pooled analyses of the methylenetetrahydrofolate reductase C677T and A1298C polymorphisms and gastric cancer risk: a huge-GSEC review. Am J Epidemiol. 2008; 167(5):505-516.

15. Gao CM, Tang JH, Cao HX, et al. MTHFR polymorphisms, dietary folate intake and breast cancer risk in Chinese women. J Hum Genet. 2009;54(7):414-418.

16. Chou YC, Wu MH, Yu JC, et al. Genetic polymorphisms of the methylenetetrahydrofolate reductase gene, plasma folate levels and breast cancer susceptibility: a case-control study in Taiwan. Carcinogenesis. 2006;27(11):2295-2300.

17. Shrubsole MJ, Gao YT, Cai Q, et al. MTHFR polymorphisms, dietary folate intake, and breast cancer risk: results from the Shanghai Breast Cancer Study. Cancer Epidemiol Biomarkers Prev. 2004;13(2): 190-196.

18. Pooja S, Carlus J, Sekhar D, et al. MTHFR 677C $>$ T polymorphism and the risk of breast cancer: evidence from an original study and pooled data for 28031 cases and 31880 controls. PLoS One. 2015;10:e120654.

19. Huang CY, Chang WS, Shui HA, et al. Evaluation of the contribution of methylenetetrahydrofolate reductase genotypes to Taiwan breast cancer. Anticancer Res. 2014;34(8):4109-4115.

20. Rai V. Methylenetetrahydrofolate reductase A1298C polymorphism and breast cancer risk: a meta-analysis of 33 studies. Ann Med Health Sci Res. 2014;4(6):841-851.

21. Widschwendter M, Jones PA. DNA methylation and breast carcinogenesis. Oncogene. 2002;21(35):5462-5482.

22. Yang X, Yan L, Davidson NE. DNA methylation in breast cancer. Endocr Relat Cancer. 2001;8:115-127.

23. Nass SJ, Herman JG, Gabrielson E, et al. Aberrant methylation of the estrogen receptor and E-cadherin $5^{\prime} \mathrm{CpG}$ islands increases with malignant progression in human breast cancer. Cancer Res. 2000;60(16):4346-4348.

24. Soares J, Pinto AE, Cunha CV, et al. Global DNA hypomethylation in breast carcinoma: correlation with prognostic factors and tumor progression. Cancer. 1999;85(1):112-118.

25. Sohn KJ, Croxford R, Yates Z, Lucock M, Kim YI. Effect of the methylenetetrahydrofolate reductase $\mathrm{C} 677 \mathrm{~T}$ polymorphism on chemosensitivity of colon and breast cancer cells to 5-fluorouracil and methotrexate. J Natl Cancer Inst. 2004;96(2):134-144.

26. Largillier R, Etienne-Grimaldi MC, Formento JL, et al. Pharmacogenetics of capecitabine in advanced breast cancer patients. Clin Cancer Res. 2006;12(18):5496-5502.

27. Cohen V, Panet-Raymond V, Sabbaghian N, Morin I, Batist G, Rozen R. Methylenetetrahydrofolate reductase polymorphism in advanced colorectal cancer: a novel genomic predictor of clinical response to fluoropyrimidine-based chemotherapy. Clin Cancer Res. 2003;9(5): $1611-1615$. 
28. Etienne MC, Formento JL, Chazal M, et al. Methylenetetrahydrofolate reductase gene polymorphisms and response to fluorouracil-based treatment in advanced colorectal cancer patients. Pharmacogenetics. 2004;14(12):785-792.

29. Shrubsole MJ, Shu XO, Ruan ZX, et al. MTHFR genotypes and breast cancer survival after surgery and chemotherapy: a report from the Shanghai Breast Cancer Study. Breast Cancer Res Treat. 2005;91(1): 73-79.

30. Liang H, Yan Y, Li T, et al. Methylenetetrahydrofolate reductase polymorphisms and breast cancer risk in Chinese population: a meta-analysis of 22 case-control studies. Tumour Biol. 2014;35(2): 1695-1701.

31. Kumar P, Yadav U, Rai V. Methylenetetrahydrofolate reductase gene C677T polymorphism and breast cancer risk: evidence for genetic susceptibility. Meta Gene. 2015;6:72-84.
32. Lu Q, Jiang K, Li Q, Ji YJ, Chen WL, Xue XH. Polymorphisms in the MTHFR gene are associated with breast cancer risk and prognosis in a Chinese population. Tumour Biol. 2015;36(5):3757-3762.

33. Martin DN, Boersma BJ, Howe TM, et al. Association of MTHFR gene polymorphisms with breast cancer survival. BMC Cancer. 2006;6:257.

34. Xu X, Gammon MD, Wetmur JG, et al. B-vitamin intake, one-carbon metabolism, and survival in a population-based study of women with breast cancer. Cancer Epidemiol Biomarkers Prev. 2008;17(8):2109-2116.

35. Babyshkina N, Malinovskaya E, Nazarenko M, et al. The effect of folate-related SNPs on clinicopathological features, response to neoadjuvant treatment and survival in pre- and postmenopausal breast cancer patients. Gene. 2013;518(2):397-404.

36. Eroğlu A, Yılmaz AE, Karasoy D. Thrombophilic polymorphisms are not associated with disease-free survival in breast cancer patients. Int J Clin Exp Med. 2015;8(5):8115-8121.

\section{Publish your work in this journal}

OncoTargets and Therapy is an international, peer-reviewed, open access journal focusing on the pathological basis of all cancers, potential targets for therapy and treatment protocols employed to improve the management of cancer patients. The journal also focuses on the impact of management programs and new therapeutic agents and protocols on

\section{Dovepress}

patient perspectives such as quality of life, adherence and satisfaction. The manuscript management system is completely online and includes a very quick and fair peer-review system, which is all easy to use. Visit http://www.dovepress.com/testimonials.php to read real quotes from published authors.

Submit your manuscript here: http://www.dovepress.com/oncotargets-and-therapy-journal 